\title{
Licenciatura em Psicologia: Debates Atuais e Relato de uma Intervenção na Formação de Professores
}

\author{
Psychology Teaching Degree: Contemporary Debates and Report of an \\ Intervention in Teachers' Training \\ Profesorado en Psicología: Debates Actuales y Relato de una Intervención en \\ la Formación de Profesores
}

\begin{abstract}
Leonardo Pereira de Lima
Psicólogo graduado na Universidade Federal de Santa Catarina. Pós-Graduando do Curso de Especialização em Gestalt Terapia da Comunidade Gestáltica - Clínica e Escola de Psicoterapia. Atua como psicólogo clínico de adultos, crianças e adolescentes. E-mail: leonardolimaemail@gmail.com
\end{abstract}

\section{Bruna da Silva}

Psicóloga graduada na Universidade Federal de Santa Catarina. Adjunta da Maiêutica Florianópolis - Instituição Psicanalitica. Psicanalista Sócia-Fundadora do espaço Flor de Lis Psicanálise. E-mail: brunasilvapsi@gmail.com

\section{Joselio Nogueira de Oliveira}

Psicólogo graduado na Universidade Federal de Santa Catarina. E-mail: joseliopsicufsc@gmail.com

\begin{abstract}
Resumo
O presente trabalho é fruto das discussões e intervenções realizadas nos Estágios Supervisionados I e II em Docência em Psicologia, disciplinas do Curso de Licenciatura em Psicologia da Universidade Federal de Santa Catarina. Ele traz inicialmente a caracterização da licenciatura em Psicologia no contexto das discussões atuais, apresenta o relato da experiência docente realizada na forma de uma oficina sobre gênero e sexualidade, dirigida a alunos de cursos de magistério e profissionais da área da educação, participantes de evento promovido pela escola onde realizamos nosso estágio. Nossa busca foi realizar uma intervenção que trouxesse reflexões e transformações genuínas, principalmente por meio de uma escuta cuidadosa, fundamental para a prática do psicólogo. As falas dos participantes apontam que atingimos nossos objetivos. Como experiência docente, a oportunidade de ministrar uma aula, em qualquer formato que seja, é uma experiência imprescindível para reflexões mais pragmáticas e próximas da realidade de quem enfrenta diariamente a docência.
\end{abstract}

Palavras-chave: educação permanente, ensino superior, formação de professores, sexualidade.

\section{Abstract}

The present paper is a result of discussions and interventions produced during Supervised Practice in Psychology Teaching I and II, subjects of the Psychology Teaching Degree of Federal University of Santa Catarina. It presents initially the characterization of the Psychology teaching degree in contemporary discussion context, and brings the report of a teaching experience effected as a workshop upon gender and sexuality, designed to students of teaching courses and education professionals, as participants of an event promoted by the school where our supervised practice took place. Our goal was to achieve an intervention that could start genuine reflection and transformation, especially through careful listening, which is fundamental to the psychologist's practice. The participants' speeches show that our goals were reached. As a teaching experience, the opportunity to teach a class at any format is an indispensable experience to build more pragmatic and closer-to-reality reflections on those who deal with the teaching work daily.

Keywords: continuing education, higher education, teachers' training, sexuality. 


\section{Resumen}

El presente trabajo es fruto de las discusiones e intervenciones realizadas en las Prácticas Docentes Supervisadas I y II en Psicología, disciplinas de la carrera de Profesorado en Psicología en la Universidade Federal de Santa Catarina. Inicialmente muestra una caracterización del Profesorado en Psicología en el contexto de las discusiones actuales, después presenta el relato de experiencia docente realizada en forma de un taller sobre género y sexualidad, destinado a alumnos de magisterio y profesionales del área de la educación, participantes del evento promovido por la escuela donde realizamos nuestra práctica. Se buscó realizar una intervención que aportara reflexiones y transformaciones genuinas, principalmente mediante una escucha cuidadosa, fundamental para la práctica del psicólogo. Las hablas de los participantes indican que alcanzamos nuestros objetivos. Como experiencia docente, la oportunidad de impartir una clase, en cualquier formato que sea, es una experiencia imprescindible para propiciar reflexiones más pragmáticas y próximas a la realidad de quien enfrenta diariamente a la docencia.

Palabras-clave: educación permanente, enseñanza superior, formación de profesores, sexualidad.

O presente artigo é fruto das discussões e intervenções realizadas nos Estágios Supervisionados I e II em Docência em Psicologia, disciplinas do Curso de Licenciatura em Psicologia da Universidade Federal de Santa Catarina, as quais foram cursadas pelos autores em dois semestres consecutivos, no ano de 2014.

As disciplinas tinham como objetivos oportunizar a discussão e análise dos processos de ensinar e aprender, promover a reflexão sobre o ensino de Psicologia em ambientes de aprendizagem e proporcionar aos cursantes a vivência de situações reais do ensino. Para tal, tivemos em sala momentos de leitura, discussão e reflexão sobre diversos textos pertinentes ao tema, alguns deles também referências para elaboração deste artigo. Visando a intervenção prática prevista na disciplina, caracterizada pela experiência do exercício de docência, realizamos visitas em uma das escolas parceiras da universidade, eleita pelo grupo para a realização da atividade. Por possuir o curso de magistério, e, portanto, disciplinas de Psicologia em seu currículo ${ }^{1}$, a instituição escolhida foi a Escola Estadual de Educação Básica Professor Aníbal Nunes Pires, localizada em Capoeiras, bairro continental da cidade de Florianópolis.

Após diversas observações e conversas com professores e alunos das turmas do curso de magistério, os autores optaram por um tema que lhes fosse familiar, relevante para essa formação e de interesse do público a quem se destinava a oficina. O tema escolhido foi "Gênero e Sexualidade: reflexões sobre possibilidades de intervenção dentro da escola". Esta atividade integrou a "Semana do Magistério", evento anual promovido pela instituição, dirigido aos alunos dos cursos de magistério da região e profissionais da área da educação.

$\mathrm{O}$ artigo trata inicialmente uma questão que se destacou em nossos encontros, eleita pelos atores como extremamente relevante para a presente discussão: a caracterização da licenciatura em Psicologia no contexto das discussões atuais. $\mathrm{O}$ artigo também apresenta, a seguir, o relato da experiência docente realizada, detalhando todo o seu processo, desde o planejamento até a execução da oficina, dialogando com os aspectos históricos que marcam a atuação da Psicologia na formação de professores. Encerra-se com nossas considerações e conclusões, com as quais esperamos contribuir para o debate sobre a licenciatura em Psicologia no Brasil e, em especial, suas contribuições para a formação de professores.

1 Apesar da orientação da Lei de Diretrizes e Bases da Educação Nacional (Brasil, 1996) de que a formação de professores para os anos iniciais de escolarização ocorra em nível superior, a Secretaria de Educação do Estado de Santa Catarina optou por manter os cursos de magistério como formação inicial para os professores que acabam atuando, em sua maioria, como auxiliares de sala. Mais informações sobre esse assunto e sobre a grade curricular do magistério, consultar Oliveira (2008). 


\section{Caracterização da licenciatura em psicologia no contexto das discussões atuais}

O panorama das discussões atuais sobre a licenciatura em Psicologia aponta questões que assumem um novo significado a partir da formulação das novas Diretrizes Curriculares Nacionais, as quais normatizam o projeto pedagógico complementar para a Formação de Professores de Psicologia. De acordo com Balduíno e Santos (2014), a necessidade de se pensar nas concepções de formação do professor, bem como em suas implicações para a atuação docente, é recolocada de forma imperativa por tais diretrizes. Para tanto, eles consideram como tema central no debate atual a reelaboração dos Projetos Políticos Pedagógicos das Instituições de ensino Superior de todo o país, entendendo que se torna uma obrigatoriedade a oferta da licenciatura nos cursos de graduação em Psicologia.

Para o Conselho Federal de Psicologia e os Conselhos Regionais de Psicologia, "essas Diretrizes, embora não apresentem impedimentos à oferta das Licenciaturas, organizam os conhecimentos específicos em ênfases e essa forma de organização precisa ser compatibilizada com as atuais Diretrizes Curriculares Nacionais para a Formação de Professores" (Conselho Federal de Psicologia, 2008, p. 76).

Assim, discutir a licenciatura em Psicologia significa pensar a formação dos jovens no Ensino Médio. Barros (2007) indica que, em 1982, período de transição da ditadura para o sistema democrático, a relação entre os psicólogos e a educação básica do cidadão passou a viver uma nova fase. De acordo com a Lei 7.044 (Brasil, 1982), foi determinado que o Ensino Médio funcionasse não mais como mera "qualificação" como constava na Lei 5.692 (Brasil, 1971), mas sim como um ensino de "preparação" para o trabalho. Passou-se a entender que havia uma diferença entre preparar-se para o mundo do trabalho e adquirir qualidades para ser um trabalhador. Esse novo posicionamento veio favorecer um projeto de formação com uma leitura mais crítica do mundo. A partir daí, a disciplina de Psicologia começa a se expandir pelos terrenos do Ensino Médio.

O Conselho Federal de Psicologia e os Conselhos Regionais de Psicologia (2008) alertam que os psicólogos, ao defenderem a volta da Psicologia ao Ensino Médio regular, inevitavelmente teriam que enfrentar o desafio de pensar a retomada e fortalecimento dos cursos de Licenciatura em Psicologia. Entendem a superação desse desafio como passo relevante na qualidade do ensino, uma vez que permitiria a aproximação do futuro psicólogo e professor de Psicologia das questões que envolvem as políticas educativas, os sistemas de ensino, orientações curriculares e outras dimensões do processo educativo, considerados fundamentais para a compreensão dos processos psicológicos no contexto educacional/escolar.

Para Leite (2007), a discussão sobre a retomada da docência em Psicologia por parte dos profissionais da área traz uma questão de fundo extremamente importante: quais as reais possibilidades para o exercício da docência em Psicologia, com um olhar crítico e numa perspectiva socialmente relevante, que justifique todos os esforços para vencer os obstáculos desse processo.

Larocca (2007) defende que a Psicologia, ao se dedicar à formação de professores, precisa repensar urgentemente a forte presença da mentalidade técnica em suas concepções de ensino, currículo e formação profissional. Além disso, observa a necessidade de desenvolver nos estudantes, que serão futuros professores, um pensamento social e político mais comprometido com a emancipação da condição humana, empreendendo rupturas nas concepções ingênuas e nas práticas educacionais tradicionais. Essa autora defende também a necessidade de contraposição à perspectiva técnica, por meio de uma perspectiva reflexiva, crítica e emancipatória, que conceba o papel do professor não como de um técnico ou simplesmente um prático, mas de um intelectual transformador da realidade em que vive, o qual saiba e tenha a coragem de questionar o sistema educacional que temos hoje em nosso país e suas múltiplas formas 
de alienação vigente. Alerta ainda para que esse professor não se deixe levar por uma formação que enfatiza o "fazer", ao invés de estimular o debate sobre a realidade social e suas demandas; nem seja envolvido por uma formação que ensina como aplicar e não por que aplicar, que ensina apenas $a$ responder e não como perguntar.

Barros (2007) salienta que a história da Psicologia no Brasil transformou seus profissionais em pessoas que pensam em termos de aplicabilidade de sua ciência. Defende que a formação de psicólogo e de professores de Psicologia é uma formação que deve estar voltada para a reflexão; voltada ainda para a pesquisa sobre o papel da Psicologia na práxis educacional, levando o professor a assumir um posicionamento crítico em direção ao papel da Educação.

Ainda em Barros (2007), temos o destaque do desinteresse do psicólogo pela profissão de professor a partir da visão que se construiu entre os próprios psicólogos sobre a Educação. Com um olhar voltado para a formação do educador profissional, a pesquisadora chama a atenção ao fato de que "mais que refletir sobre a formação do professor de Psicologia, interessa levantar questões sobre a relação entre Psicologia e Educação do cidadão" (Barros, 2007, p. 33). Além disso, questiona a distância entre o saber psicológico e os projetos de educação básica, bem como a falta de importância dada pelos psicólogos a esse fato.

Consideramos, assim como Leite (2007), que a Psicologia, como área de conhecimento acumulado e de prática social comprometida, tem contribuições relevantes para a constituição dos jovens como seres humanos críticos e transformadores, e pode contribuir de maneira significativa para a formação de professores. Diante do exposto, podemos afirmar que a formação docente em Psicologia carrega consigo uma exigência: que o professor tenha um esforço de aprofundamento e ampliação do seu universo teórico, no sentido de identificar, dentre os conhecimentos psicológicos acumulados, aqueles que melhor possibilitarão aos jovens e futuros professores a ressignificação de suas práticas.

\section{Uma experiência de Psicologia na formação de professores}

A origem do curso de magistério, como é conhecido atualmente, está na Escola Normal, a qual se consolidou no país como local de formação de professores nas primeiras décadas do século $\mathrm{XX}$, momento em que o Brasil estava passando por transformações sociais, sendo a Educação vista como um valioso recurso de poder e solução dos problemas nacionais (Sganderla, 2007).

Carvalho (2003), Oliveira (2008) e Sganderla (2007) demonstram que a Psicologia se consolidou como disciplina na formação de professores naquele período. A Educação incorporou muitos conhecimentos da Psicologia em suas práticas e métodos de ensino, principalmente os relativos ao desenvolvimento infantil, "visando instrumentalizar esses profissionais para a nova educação dentro do projeto de nação que o Brasil buscava construir nos anos 1920" (Sganderla, 2007). Ao mesmo tempo, a Educação também contribuiu com a constituição da Psicologia como campo científico reconhecido no país, mesmo antes da implantação legal da profissão de psicólogo, que só vai ocorrer em 1963.

Até a Lei de Diretrizes e Bases da Educação Nacional $^{2}$, de 1996, a formação de professores para os anos iniciais da educação básica também poderia ocorrer em nível médio, nos cursos de magistério, e assim, desde o seu início, na década de 1980, a escola escolhida para nossa experiência docente já oferecia esse curso em questão.

2 A Lei de Diretrizes e Bases da Educação Nacional (Brasil, 1996) estabelece, em seu parágrafo $4^{\circ}$, do artigo $87^{\circ}$, que "somente serão admitidos [na educação básica] professores habilitados em nível superior ou formados por treinamento em serviço", sendo que essa foi a primeira vez que uma legislação brasileira contemplou tal dispositivo. Meta essa considerada extremamente ambiciosa para a conjuntura brasileira e que ainda se mostra dificílima em se concretizar. 
Localizada em Capoeiras, bairro continental da cidade de Florianópolis, a escola foi inaugurada pela Secretaria de Estado da Educação com o intuito inicial de atender exclusivamente alunos do Ensino Médio, por meio de cursos técnicos profissionalizantes. Com funcionamento nos três turnos (matutino, vespertino e noturno), a escola vinha oferecendo à comunidade os ensinos Fundamental e Médio, assim como o curso de magistério. Porém, com o atual processo de municipalização do Ensino Fundamental, está gradativamente deixando de oferecer turmas dos anos iniciais de escolarização e concentrando-se na oferta para o Ensino Médio.

Os alunos do curso de magistério frequentam os dois primeiros anos do Ensino Médio regular, momento em que podem optar por essa formação profissional. Em 2014, estavam matriculados no magistério dessa escola cerca de 70 alunos, distribuídos em quatro turmas nos turnos matutino e noturno. As disciplinas de Psicologia - Psicologia da Educação I e II - estão presentes nos dois anos de formação específica do curso ( $3^{\circ}$ e $4^{\circ}$ ano, respectivamente) com cargas horárias de duas e uma hora, respectivamente.

Ao longo do estágio, estivemos na escola em três ocasiões para fazer observações das aulas de Psicologia da Educação nas turmas de $3^{\circ}$ e $4^{\circ}$ anos do magistério. Nas aulas em que estivemos presentes, sentimos que sua curta duração não permite que muitos temas sejam abordados, se resumindo a pouquíssimas discussões, sem aprofundamento. Percebemos também que nem todos os alunos de fato se envolvem nas conversas, indagando se tal fato acontece por desinteresse, por características pessoais, como timidez, pelas relações de poder presentes na classe, pela nossa presença ou pela combinação de dois ou mais desses fatores. Nesses primeiros contatos, tivemos poucas oportunidades de interagir com os alunos, mas foi possível fazer algumas colocações e participar de alguns pequenos debates. Nessas oportunidades, os alunos mostraram-se atentos às nossas falas, verbalizando, nos finais dos encontros, a importância de nossa presença e de nossas contribuições para suas reflexões e aprendizado.

Como parte das atividades do estágio, realizamos também uma entrevista com um dos professores do curso do magistério ${ }^{3}$, professor este que se destaca como um importante elo e um dos principais agentes na interlocução e parceria entre a escola e a UFSC, concretizadas por meio dos estágios supervisionados da disciplina Docência em Psicologia e do Programa Institucional de Bolsa de Incentivo à Docência - PIBID ${ }^{4}$ Psicologia. Questionado quanto às suas expectativas com a presença dos estagiários, o entrevistado manifestou que esperava que pudéssemos trazer novas reflexões, além de contribuir com novas bibliografias e diferentes metodologias de ensino.

3 Este professor, graduado em Pedagogia com habilitação em magistério pela UDESC, e com mestrado em Educação pela Univali, atualmente é o único a ministrar a disciplina Psicologia da Educação nessa escola, trabalhando com as quatro turmas do magistério ali existentes. Leciona também as disciplinas Filosofia da Educação, Didática da Educação Infantil, Estágio Curricular da Educação Infantil e Estágio Curricular dos Anos Iniciais. O fato de lecionar várias outras disciplinas e não somente a de Psicologia não é uma situação isolada; o que se deve à pequena carga horária da disciplina de Psicologia no curso (3 horas/aula no total), o que exige que o professor complete sua carga horária com outras disciplinas (Oliveira, 2008).

$4 \mathrm{O}$ Programa Institucional de Bolsa de Incentivo à Docência (PIBID) é um programa da CAPES que teve seu primeiro edital lançado pelo Ministério da Educação em dezembro de 2007, tendo como público-alvo os cursos de licenciatura das universidades públicas. Na UFSC, o PIBID Psicologia começou nessa escola em 2010. O programa tem por objetivo incentivar a formação inicial nas licenciaturas e fortalecer a escola pública como espaço de formação (Carvalho, \& Ramos, 2014). 


\section{Planejamento da atividade}

Munidos dessas informações, começamos a pensar o modo como poderíamos atuar com as turmas do magistério, buscando um tema que pudesse efetivamente instrumentalizar os alunos no seu futuro exercício profissional e que atendesse às expectativas de todos os envolvidos. Em nossas conversas, observações e visitas, foi inevitável surgirem questionamentos e problematizações acerca das expressões de sexualidade, tema presente em qualquer sala de aula e, normalmente, associado ao trabalho do psicólogo. Esse fato confirma diversos estudos que apontam as dificuldades dos educadores em lidar com as expressões da sexualidade que aparecem no cotidiano escolar (Ávila, Toneli, \& Andaló, 2011; Costa, \& Ribeiro, 2011; Gesser, Oltramari, Cord, \& Nuernberg, 2012; Nardi \& Quartiero, 2012; Yared, 2011), sendo a relevância e importância do tema um consenso na atualidade.

Nessa fase inicial de planejamento de nossas atividades, surgiu o convite da coordenação da escola para que realizássemos uma oficina durante a "Semana do Magistério", evento promovido por aquela instituição há mais de dez anos e que conta com a parceria das instituições de ensino que oferecem magistério na grande Florianópolis, além de professores das redes públicas. Assim, atendendo a essa demanda, e com a experiência prévia de um dos autores deste artigo no projeto de extensão "Educação Continuada de Professores em Gênero e Sexualidade", optamos pela realização de uma oficina, nomeada "Oficina Gênero e Sexualidade: reflexões sobre possibilidades de intervenção dentro da escola".

A oficina baseou-se na experiência do projeto de extensão citado, realizado pela parceria entre a Secretaria Municipal de Educação de Florianópolis e o Laboratório de Psicologia Escolar e Educacional (LAPEE), da UFSC, em 2012. Dessa forma, assim como no projeto, nos orientamos pelo conceito de sexualidade proposto pela cartilha Gênero e Diversidade na Escola, no qual:

As definições atuais da sexualidade abarcam, nas ciências sociais, significados, ideais, desejos, sensações, emoções, experiências, condutas, proibições, modelos e fantasias que são configurados de modos diversos em diferentes contextos sociais e períodos históricos. Tratase, portanto, de um conceito dinâmico que vai evolucionando e que está sujeito a diversos usos, múltiplas e contraditórias interpretações, $e$ que se encontra sujeito a debates e a disputas políticas. Refere-se às elaborações culturais sobre os prazeres e os intercâmbios sociais e corporais que compreendem desde o erotismo, o desejo e o afeto até noções relativas à saúde, à reprodução, ao uso de tecnologias e ao exercício do poder na sociedade (BRASIL, 2009, p. 112).

Vale mencionar também que a concepção de homem que subsidiou tanto o projeto como nossa oficina foi a da Psicologia Histórico-Cultural, de Vygotsky (1992, 2000), na qual o homem se constitui a partir da apropriação dos múltiplos significados presentes nas relações intersubjetivas que o constituem como sujeito e mediam seu modo de pensar, sentir e agir no mundo. Portanto, cada homem é uma síntese inacabada das múltiplas relações que possui com a cultura e a sociedade, configuradas na processualidade. É um ser em constante transformação.

Sabemos que a educação sexual é um direito da criança e, apesar de não existir até o momento nenhuma citação na legislação brasileira que garanta a educação sexual como componente curricular das escolas, documentos como os Parâmetros Curriculares Nacionais (Brasil, 1999); o Estatuto da Criança e do Adolescente (Brasil, 1990); Plano Nacional de Políticas para as Mulheres (Brasil, 2004a); o Programa Brasil Sem Homofobia (Brasil, 2004b); o Caderno Gênero e Diversidade Sexual na Escola (Brasil, 2009); e o Programa de Saúde na Escola - PSE (Brasil, 2006) apoiam e respaldam o desenvolvimento de práticas profissionais nesse campo.

A ideia foi realizar uma oficina que envolvesse os participantes de forma afetiva, sensibilizandoos para que os mitos, tabus e preconceitos 
relacionados à sexualidade tivessem ali um início de desconstrução.

No planejamento, definimos como ementa as concepções de sexualidade, suas implicações nas práticas educativas e as relações de gênero no contexto dos anos iniciais da escolarização. Os objetivos específicos foram instrumentalizar as condições para: identificar as concepções de sexualidade predominantes na contemporaneidade; relacionar as concepções de sexualidade e seus efeitos em suas próprias ações no cotidiano escolar; e compreender o previsto na legislação vigente, de modo a orientar sua ação diante das expressões de sexualidade no contexto educacional.

Foi previsto inicialmente um tempo de duas horas e trinta minutos de atividade, com a seguinte metodologia: iniciar a oficina com a realização de uma apresentação dos coordenadores da oficina e dos participantes, seguida de uma atividade de "quebra-gelo", onde seriam desenhados pelos participantes corpos humanos masculinos e femininos com todas as suas partes, elaborando uma história para os personagens criados, com o posterior compartilhamento no grupo. Faríamos, então, uma conversa aberta sobre casos relacionados à sexualidade vivenciados pelos presentes, elegendo uma das situações apresentadas para posterior discussão. $\mathrm{Na}$ sequência, leitura de resumos das concepções de sexualidade presentes na contemporaneidade (citadas a seguir) e divisão da turma em três grupos para elaboração de uma solução para o caso escolhido. Cada grupo pensaria no caso sob a ótica de sua respectiva concepção de sexualidade e então faria a exposição de suas conclusões no grande grupo. Por fim, realizaríamos uma roda de conversa para perguntas, esclarecimento de dúvidas e impressões sobre a oficina.

Porém, vivenciamos os imprevistos presentes na realidade escolar, já apontada por Perrenoud (1997), em que os comunicados, apresentações, atividades culturais e lanche ocuparam grande parte do tempo do encontro, reduzindo para uma hora o tempo disponível para nossa oficina. Com isso, foi necessário reformular o planejamento e, assim, decidimos retirar do cronograma a atividade de desenho dos corpos, a qual possibilitaria um melhor aquecimento, criação de vínculo e maior interação dos participantes, o que de fato dificultou a integração dos mesmos na atividade.

A oficina foi realizada no auditório, um lugar amplo, com duzentos e quarenta lugares, com computador e projetor disponível, além de um sistema de som e microfone, o qual teve que ser utilizado devido à dimensão do local. Compareceram à oficina cerca de trinta participantes, todas do sexo feminino, na sua grande maioria estudantes do curso de magistério, já atuantes na área profissional. Elas mostraramse tímidas, inicialmente. Feitas as apresentações dos nomes e instituições de origem, distribuímos o material impresso e pedimos que se dividissem em três grupos, conforme numeração no verso do material, de acordo com cada concepção de sexualidade apresentada. Utilizamos as seguintes definições das concepções de sexualidade presentes na contemporaneidade:

- Concepção médico-higienista: "reduz a sexualidade à genitalidade, considerando-a um 'problema' de saúde pública. Não está em jogo a formação do sujeito e sim a informação de como se evitar o contágio de doenças sexualmente transmissíveis e de gravidez caracterizada como precoce" (Yared, Barros, \& Gesser, 2010, p.3);

- Concepção moral-religiosa: "ideia de um amor 'fraternal' entre os cônjuges, descartando a discussão do prazer, do desejo e da possibilidade da realização sexual fora da intenção de procriar, fora do matrimônio, da monogamia e das orientações sexuais (bi e homossexualidade)" (Santa Catarina, 1998, p.15);

- Concepção histórico-cultural: "aponta a sexualidade como produzida no contexto das relações e como exclusivamente humana" (Yared et al., 2010, p.3). 
Depois da leitura de cada concepção, foi realizada, então, a projeção de um caso $^{5}$ na tela do auditório. Pedimos que começassem as discussões nos pequenos grupos, com o acompanhamento de um coordenador da oficina em cada grupo.

No grupo em que o tema foi a concepção médico-higienista, as participantes demoraram a se engajar no processo, algumas sentadas distantes do grupo, outras de costas umas para as outras, conversando em paralelo e sem adesão à atividade proposta. Com a intervenção da coordenadora do grupo, foi possível que começassem a pensar em situações em que a concepção médicohigienista estava presente. $\mathrm{O}$ que mais apareceu, porém, foram as histórias que as participantes queriam contar sobre o que já vivenciaram, como acontece nas suas famílias e nas escolas em que trabalham.

No grupo em que o tema foi a concepção moralreligiosa, as falas das participantes reafirmavam as crenças dessa concepção. Durante grande parte do tempo, os participantes relataram situações vivenciadas por eles particularmente, deixando de problematizar e de estabelecer um olhar crítico sobre o caso apresentado.

Já com relação à concepção histórico-crítica, o trabalho do coordenador foi importante para direcionar e questionar cada posicionamento, afim de entendimento do proposto e de atingir o objetivo da atividade. As participantes apresentaram casos de seu cotidiano, buscando respostas ou trazendo intervenções que não iam ao encontro da concepção histórico-crítica. Também foram trazidas soluções para o caso apresentado que condiziam, de maneira geral, com a concepção proposta nesse grupo, mas que apresentavam traços e influências de uma concepção moralreligiosa ou médico-higienista, evidenciando o quanto essas três concepções fazem parte de nossa constituição como cidadãos civilizados do mundo moderno.

Abrimos o debate para toda a turma para a apresentação das discussões realizadas em cada grupo. Desse momento, alguns pontos merecem destaque, como, por exemplo, a fala de uma das participantes que enfatizou a dificuldade de fazer com que os alunos tivessem uma vivência de uma sexualidade "normal". Entendemos que ela buscava uma confirmação de sua afirmação, que representa o senso comum da concepção moral-religiosa de sexualidade, pois defende algo preestipulado entendido como normalidade. O questionamento sobre o que seria "normal" é fundamental para a desconstrução de estereótipos cristalizados, um dos objetivos da oficina.

A possibilidade de mudança de posicionamento, trazido pelo questionamento de uma das participantes, é outro destaque. Refletir e problematizar sobre aquilo que lhe haviam ensinado como verdade, permitiu ao grupo perceber que a mudança é possível.

No final, os participantes lamentaram a falta de tempo, falando da necessidade que sentiam de momentos como esse e em debater o tema sexualidade em específico.

\section{Considerações Finais}

Sendo a atuação do professor constituída pelo domínio do conhecimento teórico, mas perpassada por sua historicidade, suas emoções e sua constituição como ser no mundo, entendemos que a Psicologia pode trazer inúmeras contribuições para esse processo, contribuições até mesmo solicitadas pelo professor do magistério que entrevistamos, quando manifestou seu desejo de

5 Devido à redução do tempo disponível, mudamos a proposta inicial dos participantes trazerem casos de seu cotidiano. Foi apresentado um caso fictício, elaborado pelos autores deste artigo: "Maria é professora do primeiro ano e tem percebido que, nas últimas semanas, João, frequentemente, está com as mãos dentro das suas calças, aparentemente, manipulando o pênis. Ela está preocupada com esse comportamento e não sabe como agir. Também tem medo dos efeitos disso na turminha e no que os pais dos alunos podem pensar sobre isso". 
que lhe fossem apresentadas em nossa intervenção novas metodologias de ensino.

Nossa busca foi realizar uma intervenção que trouxesse reflexões e transformações genuínas. Apesar do breve tempo que tivemos, as falas de feedback dos participantes apontam que atingimos nossos objetivos, mostrando que houve abertura para ressignificações de posicionamentos, por meio de questionamentos e diálogos construtivos e transformadores. Isso pôde ser proporcionado pela escuta cuidadosa, a qual deve estar presente em qualquer profissional da Psicologia, como algo imprescindível para encontrar os momentos e as formas mais adequadas para intervenção, quando as resistências e os desconfortos emergem na audiência. Esse é um saber da Psicologia que pode contribuir no processo ensino-aprendizagem, em especial na forma de organizar as atividades orientadoras de ensino, no sentido de constituir nos alunos necessidades autênticas do objeto de aprendizagem (Moura, 2010).

Como experiência docente, entendemos que a realização da oficina atendeu aos objetivos das disciplinas. Pudemos fazer todo o planejamento e cronograma pensando no público-alvo e nos objetivos que queríamos atingir. Os imprevistos com o tempo para a atividade nos deram uma vivência do que acontece de real em sala: muitas vezes, pelos motivos mais inesperados, os professores têm que fazer alterações naquilo que programaram e adaptarem-se às condições que se apresentam de fato. A vivência de ministrar uma aula, na forma que seja, é uma experiência única que nos faz sair do campo apenas teórico para reflexões mais pragmáticas e próximas da realidade de quem enfrenta diariamente a docência.

\section{Referências}

Ávila, A. H., Toneli, M. J. F., \& Andaló, C. S. A. (2011). Professores/as diante da sexualidade-gênero no cotidiano escolar. Revista Psicologia em Estudo, 16(2), 289-298. doi: 10.1590/S1413-73722011000200012

Balduino, J. C., \& Santos, I. C. G. (2014). A formação do professor de Psicologia no âmbito das Diretrizes Curriculares Nacionais: concepções e implicações para a atuação docente. Relatório não publicado de Iniciação Científica.

Barros, C. C. (2007). Reflexões sobre a formação de professores de Psicologia. Temas em Psicologia, 15, 33-39.

Brasil. (1971). Fixa Diretrizes e Bases para o ensino de $1^{\circ}$ e $2^{\circ}$ graus, e dá outras providências: ${ }^{\circ} 5.692 / 71$. Brasília: Senado Federal. Recuperado de http:// www2.camara.leg.br/legin/fed/lei/19701979/ lei569211agosto1971357752publicacaooriginal1pl.html

Brasil. (1982). Altera dispositivos da Lei ${ }^{\circ}$ 5.692, de 11 de agosto de 1971, referentes à profissionalização do ensino de $2^{\circ}$ grau: $n^{\circ} 7.044 / 82$. Brasília: Senado Federal. Recuperado de http://www2.camara.leg.br/legin/fed/lei/19801987/ lei704418outubro1982357120publicacaooriginal1pl. html

Brasil. (1990). Lei n. 8069, de 13 de junho de 1990. Dispõe sobre o Estatuto da Criança e do Adolescente e dá outras providências. Lex: Coleção de Leis do Brasil, Brasília. 4, pp. 2379.

Brasil. (1996). Lei de Diretrizes e Bases da Educação Nacional: $n^{\circ}$ 9394/96. Brasília: Senado Federal. Recuperado de http://portal.mec.gov.br/arquivos/pdf/ldb.pdf
Brasil. (1999). Parâmetros Curriculares Nacionais: Orientação Sexual. Brasília: Secretaria de Educação Fundamental - MEC. Recuperado de http://portal.mec. gov.br/seb/arquivos/pdf/orientacao.pdf

Brasil. (2004a). Plano Nacional de Políticas para as Mulheres. Brasília: Secretaria Especial de Políticas para as Mulheres. Recuperado de http://bvsms.saude.gov.br/ bvs/publicacoes/pnpm_compacta.pdf

Brasil. (2004b). Programa de combate à violência e à discriminação contra GLTB e promoção da cidadania homossexual. Brasília: Conselho Nacional de Combate à Discriminação - Ministério da Saúde. Recuperado de http://bvsms.saude.gov.br/bvs/publicacoes/brasil_sem_ homofobia.pdf

Brasil. (2006). Diretrizes para implantação do Projeto Saúde e Prevenção nas Escolas. Brasília: Secretaria de Vigilância em Saúde - Ministério da Saúde. Recuperado de http:// sistemas.aids.gov.br/saudenaescola2010/sites/default/ files/Diretrizes_de_Implementacao.pdf

Brasil. (2009). Gênero e diversidade na escola: formação de professoras/es em Gênero, Orientação Sexual e Relações Étnico-Raciais Livro de conteúdo. Rio de Janeiro: Secretaria de Políticas para as Mulheres CEPESC. Recuperado de http://estatico.cnpq.br/portal/ premios/2013/ig/pdf/genero_diversidade_escola_2009. pdf

Carvalho, D. (2003). As contribuições da Psicologia para a formação de professores: algumas questões para 
debate. In C. Maraschin, L. Freitas, \& D. C. Carvalho (orgs.), Psicologia e Educação: multiversos sentidos, práticas e experiências (p. 79-88). Porto Alegre: Editora da Universidade Federal do Rio Grande do Sul.

Carvalho, D., \& Ramos, D. K. (2014). Contribuições do Pibid Psicologia à formação docente e ao fortalecimento da licenciatura. In A. V. Garcia, \& A. D’Agostini (Orgs.) Reflexões sobre a formação de professores e PibidUFSC. (pp. 129-150). Tubarão: Gráfica Copiart Editora.

Conselho Federal de Psicologia \& Conselhos Regionais de Psicologia. (2008). Ano da Psicologia na Educação: textos geradores. Brasília: CFP. Recuperado de http://site.cfp. org.br/wpcontent/uploads/2008/08/anoeducacao.pdf

Costa, A. P., \& Ribeiro, P. R. M. (2011). Ser professora, ser mulher: Um estudo sobre concepções de gênero e sexualidade para um grupo de alunas de pedagogia. Revista Estudos Feministas, 19(2), 475-489. doi: 10.1590/ S0104-026X2011000200011

Gesser, M., Oltramari, L. C., Cord, D., \& Nuernberg, A. H. (2012). Psicologia Escolar e formação continuada de professores em gênero e sexualidade. Psicologia Escolar e Educacional, 16(2), 229-236. doi: 10.1590/S141385572012000200005

Larocca, P. (2007). Ensino de Psicologia e seus fins na formação de professores: Uma discussão mais que necessária. Temas em Psicologia, 15, 57-68.

Leite, S. A. S. (2007). Psicologia no ensino médio: Desafios e perspectivas. Temas em Psicologia, 15, 11-21.

Moura, M. O. (Org). (2010). A atividade pedagógica na teoria histórico-cultural. Brasília: Liber Livro.

Nardi, H. C., \& Quartiero, E. (2012). Educando para a diversidade: Desafiando a moral sexual e construindo estratégias de combate à discriminação no cotidiano escolar. Sexualidad, Salud y Sociedad, 11, 59-87.

Oliveira, A. B. (2008). Criança e infância nas disciplinas de psicologia dos cursos de magistério: um estudo na rede estadual de educação da região metropolitana de Florianópolis (Dissertação de Mestrado). Florianópolis, Brasil: Universidade Federal de Santa Catarina.

Perrenoud, P. (1997). Práticas pedagógicas, profissão docente e formação - perspectivas sociológicas. Lisboa: Dom Quixote.

Santa Catarina. (1998). Proposta Curricular de Santa Catarina: educação infantil, ensino fundamental e médio: temas multidisciplinares (p. 160). Florianópolis: COGEN.

Sganderla, A. P. (2007). A psicologia na constituição do campo educacional brasileiro: a defesa de uma base científica da organização escolar. (Dissertação de Mestrado). Florianópolis, Brasil: Universidade Federal de Santa Catarina.

Vygotsky, L. S. (1992). Obras Escogidas. Tomo II. Madrid: Visor Distribuiciones.

Vygotsky, L. S. (2000). Manuscrito de 1929. Educação \& Sociedade, 71, 21-44. doi: 10.1590/S010173302000000200002

Yared, Y. B. (2011). A educação sexual na escola: tensões e prazeres na prática pedagógica de professores de ciências e biologia. (Dissertação de Mestrado). Lages, Brasil: Universidade do Planalto Catarinense.

Yared, Y. B., Barros, F., \& Gesser, M. (2010). Programa de atenção à sexualidade na infância e na adolescência na rede pública municipal de ensino de Lages/SC. In Fazendo Gênero, 9. Anais, 1-10. Florianópolis: Instituto de Estudos de Gênero. Recuperado de http://www. fazendogenero.ufsc.br/9/resources/anais/1278298747_ ARQUIVO_ArtigoFazendoGenero2010.pdf 